\title{
BMJ Open Social epidemiology of excess weight and central adiposity in older Indians: analysis of Study on global AGEing and adult health (SAGE)
}

\author{
Sudipta Samal, ${ }^{1}$ Pinaki Panigrahi, ${ }^{2}$ Ambarish Dutta ${ }^{1}$
}

To cite: Samal S, Panigrahi P, Dutta A. Social epidemiology of excess weight and central adiposity in older Indians: analysis of Study on global AGEing and adult health (SAGE). BMJ Open 2015;5:e008608. doi:10.1136/bmjopen-2015008608

- Prepublication history and additional material is available. To view please visit the journal (http://dx.doi.org/ 10.1136/bmjopen-2015008608).

Received 27 April 2015 Revised 11 August 2015 Accepted 18 September 2015

\section{CrossMark}

${ }^{1}$ Centre for Disease Epidemiology and Surveillance, Asian Institute of Public Health,

Bhubaneswar, Odisha, India ${ }^{2}$ Center for Global Health and Development, University of Nebraska Medical Center, Omaha, Nebraska, USA

Correspondence to Dr Ambarish Dutta; adutta@aiph.ac.in

\section{ABSTRACT}

Objectives: We aimed to estimate the prevalence of overweight and obesity, represented by extra body weight and abdominal circumference, among older Indians; and to characterise the social pattern of obesity and measure the magnitude of hypertension attributable to it.

Setting: A nationally representative sample of older Indians was selected from 6 Indian states, including Rajasthan, Uttar Pradesh, West Bengal, Assam,

Maharashtra and Karnataka, as a part of the multicountry Study on global AGEing and adult health (SAGE).

Participants: Indians aged 50 years or more $(n=7273)$ were included in the first wave of the SAGE (2010), which we used in our study.

Primary and secondary outcome measures: The primary outcome measures included excess weight (EW), defined by body mass index (BMI) $>25 \mathrm{~kg} / \mathrm{m}^{2}$, and central adiposity (CA), defined by waist circumference $>90 \mathrm{~cm}$ for men and $>80 \mathrm{~cm}$ for women. The secondary outcome included hypertension, defined by systolic blood pressure $>139$ or diastolic blood pressure $>79 \mathrm{~mm} \mathrm{Hg}$, or by those receiving antihypertensive medications.

Results: $14 \%$ of older Indians possessed EW, whereas $35 \%$ possessed $\mathrm{CA} ; 50.9 \%$ of the wealthier third and $27.7 \%$ of the poorer two-thirds have CA; the proportions being $69.1 \%$ and $46.2 \%$, respectively, in older women. Mostly wealth (adjusted OR for CA: 4.36 (3.23 to 5.95) and EW: 4.39 (3.49 to 5.53)), but also urban residence, privileged caste, higher education, white-collared occupation and female gender, were important determinants. One of 17 older Indians overall and 1 of 18 in the poorer $70 \%$ suffered from CA-driven hypertension, independent of BMI.

Conclusions: The problem of $\mathrm{CA}$ and its allied diseases is already substantial and expected to rise across all socioeconomic strata of older Indians, though currently, $\mathrm{CA}$ affects the privileged more than the underprivileged, in later life. Population-based promotion of appropriate lifestyles, with special emphasis on women, is required to counteract prosperity-driven obesity before it becomes too entrenched and expensive to uproot.

\section{Strengths and limitations of this study}

- The nationally representative sample of $50+$ years old Indians allowed for country-wide prevalence estimates. It also allowed for nationwide generalisability of association estimates.

- The large data set helped obtaining precise estimates.

- The cross-sectional nature of the data had the potential to partially affect the causal inferences, but to a negligible extent, given the strong plausibility of the associations and their temporal relationships.

\section{INTRODUCTION}

Developed nations around the world underwent demographic transitions during the last century, marked by declining mortality, increasing lifespan and diminishing fertility, leading to ageing of their populations. ${ }^{1}$ This was inseparably linked to the epidemiological transition, marked by substantial decline of undernutrition, infection and childbirthrelated diseases, and the rise of chronic lifestyles and age-related non-communicable illnesses such as cardiovascular diseases, diabetes, cancer and musculoskeletal disorders. ${ }^{1}$ These transitions, mainly driven by progressive economic prosperity, also ushered in significant changes in lifestyle and nutritional practices in those societies. Consequently, rapidly growing body weight and abdominal girth beyond an optimum range, commonly referred to as 'obesity', in the literature (and also in this document hereafter), emerged as a major forerunning risk factor leading to a surge of chronic diseases of epidemic proportions, especially affecting their older citizens; similar trends are currently also being noticed in many middleincome countries, which have experienced economic transitions similar to the developed economies. $^{2-5}$ 
Emerging economies, such as India, are likely to follow these transitions of the industrialised nations with a lag of a few decades, ${ }^{45}$ as their economies prosper. It is already evident, from available reports, that obesity and its allied diseases are on the rise, ${ }^{6-8}$ but the nexus of poverty, undernutrition and infectious diseases also remains a substantial health problem, ${ }^{2}{ }^{9}$ presenting a so-called 'double burden' to India. ${ }^{10} 11$

Some authors ${ }^{12}$ have contended that attention needs to be paid to this surge of non-communicable diseases by the health policymakers of India, whereas others ${ }^{12-15}$ have argued that the problem is still restricted to a minority of affluent Indians, and that the majority of Indians, who are underprivileged, are mostly spared. So, clamour for increased attention and public investment can inequitably divert scant health resources from the infectious and childbirth-related diseases of undernutrition, and poverty-the primary concerns affecting the overwhelming majority of underprivileged Indians.

Hence, it is important, in contemporaneous India, to study excess weight (EW) and abdominal circumference, critical forerunning risk factors for noncommunicable diseases, and their social patterns, so that public policy can be appropriately informed for evidence-based equitable action. Otherwise, it may be difficult to avert an avoidable experience that many developed nations inherited from their transition, that is, a massive surge in obesity and related morbidity as well as mortality. ${ }^{45}$

Prevalence and social patterning of obesity has been sparingly studied in India; these studies have been mostly on children, adolescents ${ }^{16}{ }^{17}$ and young adults, ${ }^{18} 19$ and also mostly in smaller samples restricted to regions or urban centres; but few studies have been conducted on older adults, among whom EW and adiposity have very important effects with regard to chronic age-related diseases and debilitating disabilities, ${ }^{10} 2021$ and who are also experiencing dwindling social support from the rapidly transitioning Indian family system, which traditionally remained a mainstay of support in later life. Also, the social determinants in the existing literature had mostly been studied using composite 'class' or 'status' variables while testing their association with obesity, and they had hardly been studied individually, which many feel can be critical for nation-specific social characterisation of obesity and its mitigation. ${ }^{4}$ Moreover, the different forms of obesity, such as the generalised and abdominal variety, merit separate attention, especially for South Asians, who have the propensity to accumulate excess adipose tissue disproportionate to their weights. ${ }^{22} 23$

Therefore, we aimed at estimating the prevalence and social pattern of EW and abdominal obesity-among Indians aged 50 years and more-in a nationallyrepresentative sample, and to then explore their relationship with individual social determinants. To put the problem into perspective, we aimed at measuring the magnitude of hypertension attributable to obesity; hypertension being one of the major outcomes of obesity and one of the classical proximal risk factors of cardiovascular disease. ${ }^{24} 25$

\section{METHODS \\ Sample}

The Study on global AGEing and adult health (SAGE) is an ongoing multicountry study on ageing, initiated by the WHO. ${ }^{26}$ SAGE is aligned to similar prominent studies of ageing: Health and Retirement Survey (HRS) ${ }^{27}$ of the USA, Study of Health, Ageing and Retirement (SHARE) of Europe, and English Longitudinal Study on Ageing (ELSA) ${ }^{28}$ The first wave (2010) of the SAGE survey ( $\mathrm{n}=7273$ ) was conducted on a nationally representative probability sample of Indians aged 50 years or more, which we analysed. The sampled Indian states included Rajasthan, Uttar Pradesh, West Bengal, Assam, Maharashtra and Karnataka, which were selected using a multistage, stratified clustered sample design, the stratifying criteria being their geographic location and level of development and representative enough of the countrywide variation in geography and development.

\section{Measurement}

Body mass index (BMI) was calculated as measured weight $(\mathrm{kg}) /$ measured height $(\mathrm{m})^{2}$ and then categorised into an ordered variable: 0-18.5: underweight; $18.5-24.9$ : normal; and $>25$ : EW. The cut-point for binary BMI was $25 \mathrm{~kg} / \mathrm{m}^{2}$; people with BMI $>25 \mathrm{~kg} / \mathrm{m}^{2}$ were referred to as having EW, which includes obese as well as overweight groups of the conventionally used categories. ${ }^{6}$ Central Adiposity (CA) was defined by waist circumference $>90 \mathrm{~cm}$ and $>80 \mathrm{~cm}$ among males and females, respectively. ${ }^{29}$ The social determinants were: education, wealth, caste, occupation and area of residence (setting). Educational attainment was collapsed into three categories from the originally recorded seven-level 3: university graduate or postgraduate; level 2: secondary or higher secondary and level 1: primary education or never been to school. Household assets, a proxy for wealth, were originally data counted on a scale of $0-17$ and then converted to quintile. Caste consisted of Scheduled Caste (SC-the most underprivileged under the Indian caste system), Scheduled Tribe (ST-indigenous tribal people), other (other than SC/ST) and no caste (not conforming to the Indian caste system). Occupation was categorised as a four-level variable -0 : no paid work; 1 : minimally skilled or subsistence; 2: semiskilled; 3: whitecollared. area of residence was dichotomised (urban/ rural). Tobacco users of smoked as well as smokeless forms were considered as never, previous and current users; with the same for alcohol users.

Hypertension $(\mathrm{Y} / \mathrm{N})$ was defined when the average of three measured systolic blood pressure tests exceeded $139 \mathrm{~mm} \mathrm{Hg}$ and/or the average of three measured diastolic blood pressure tests exceeded $89 \mathrm{~mm} \mathrm{Hg}$ 
and/or the individual received antihypertensive medications. ${ }^{25}$

\section{Statistical analysis}

Initially, prevalence of EW and CA among the population was determined. Distribution of three-level BMI (underweight, normal and EW) across its various categorical risk factors was described using contingency tables, and differences were tested using $\chi^{2}$ test.

The strengths of association between binary BMI (EW: $\mathrm{Y} / \mathrm{N}$ ) and each individual social determinant were estimated using logistic regression, initially minimally adjusted for age and gender; followed by a fully adjusted model that additionally included all social determinants such as education, assets, caste, occupation and place of residence, and also tobacco-use status as a confounder, to estimate their independent effects. Standardised regression coefficients were calculated to compare the effect sizes, as they were measured in different scales. Similar statistical methods were repeated with CA as binary outcome. Interaction between risk factors and gender was tested in the models.

The Population Attributable Fraction (PAF) of CA (both BMI adjusted and BMI unadjusted) was calculated in relation to the prevalence of hypertension in the population and subpopulations, using the aflogit ${ }^{30}$ package of STATA (V.12.1) (StataCorp, College Station, Texas, USA), following post-Poisson regression models; with the models also controlling for the effects of smoking and alcohol use. For other analyses R software $\left(\right.$ V.3.1.1 ${ }^{31}$ was used.

\section{RESULTS}

Overall, $14 \%$ (13.69-14.31\%) of Indians aged 50 years and above $(\mathrm{n}=912)$ have EW, whereas $34.5 \%$ (33.72$35.28 \%) \quad(\mathrm{n}=2255)$ have CA (table 1). Prevalence of underweight was $35 \%$. Of EWs, $84 \%$ possessed CA, whereas only $43 \%$ CAs possessed EW (figure 1). The prevalence of CA was consistently higher than EW across all social determinant groups, as shown below.

Prevalence of EW (table 2) and CA (table 3) was nearly twice in older Indian women than in men (EW: $18 \%$ women vs $10.5 \%$ men and CA: $35.5 \%$ women vs $19.4 \%$ men, $\mathrm{p}<0.0001)$. EW and CA were more prevalent among the highly educated (EW: 28.2\% highest educated vs $11.9 \%$ lowest educated, CA: $48 \%$ highest vs $33 \%$ lowest educated $(\mathrm{p}<0.0001)$; a consistent gradient was apparent across the three categories of education. Prevalence of EW in urban and rural areas was 25.5\% and $10.3 \%$, respectively $(\mathrm{p}<0.0001)$; comparable to the distribution of CA $(51.4 \%$ and $29.2 \%$, respectively, $\mathrm{p}<0.0001)$. Both EW and CA had significantly different distribution across occupational group; white-collared category having $26.1 \% \mathrm{EW}$ and $42.8 \% \mathrm{CA}$, compared to $8.9 \%$ and $26.1 \%$ of EW and CA, respectively, among unskilled/subsistence workers $(\mathrm{p}<0.0001)$. Almost $30 \%$ in the top affluent quintile possessed EW compared to
Table 1 Distribution of demographic characteristics, social determinants, excess weight and central adiposity in Indians aged 50 years and older in SAGE sample $(\mathrm{n}=7273)(2007-2010)$

\begin{tabular}{|c|c|c|}
\hline & Number & Per cent \\
\hline \multicolumn{3}{|l|}{ Age (vears) } \\
\hline $50-59$ & 3234 & 44 \\
\hline $60-80$ & 3665 & 50 \\
\hline$\geq 80$ & 374 & 5 \\
\hline \multicolumn{3}{|l|}{ Gender } \\
\hline Male & 3682 & 51 \\
\hline Female & 3591 & 49 \\
\hline \multicolumn{3}{|l|}{ Caste } \\
\hline No caste or tribe & 1132 & 17 \\
\hline Other & 3979 & 60 \\
\hline Scheduled Caste & 1102 & 17 \\
\hline Scheduled Tribe & 400 & 6 \\
\hline \multicolumn{3}{|l|}{ Occupation } \\
\hline No paid occupation & 1863 & 28 \\
\hline $\begin{array}{l}\text { Traditional subsistence or } \\
\text { unskilled }\end{array}$ & 3428 & 52 \\
\hline Semi-skilled & 914 & 14 \\
\hline Skilled or white-collar & 425 & 6 \\
\hline \multicolumn{3}{|l|}{ Education } \\
\hline Illiterate or up to primary & 5105 & 77 \\
\hline Secondary & 1213 & 18 \\
\hline Higher secondary and higher & 328 & 5 \\
\hline \multicolumn{3}{|l|}{ Quintiles of asset } \\
\hline Lowest $(0-4)$ & 1464 & 20 \\
\hline Lower middle (4-6) & 1760 & 24 \\
\hline Middle $(6-8)$ & 1717 & 24 \\
\hline Upper middle $(8-10)$ & 1265 & 17 \\
\hline Highest $(10-16)$ & 1049 & 14 \\
\hline \multicolumn{3}{|l|}{ Area of residence } \\
\hline Urban & 1899 & 26 \\
\hline Rural & 5374 & 74 \\
\hline \multicolumn{3}{|l|}{ BMl: $\mathrm{kg} / \mathrm{m}^{2}$} \\
\hline Underweight $(<18.5)$ & 2270 & 35 \\
\hline Normal (18.5-24.9) & 3246 & 50 \\
\hline Excess weight $(\geq 25)$ & 912 & 14 \\
\hline \multicolumn{3}{|l|}{$\mathrm{CA}$} \\
\hline No & 4209 & 65 \\
\hline Yes & 2255 & 35 \\
\hline \multicolumn{3}{|c|}{$\begin{array}{l}\text { For the following variables the number of observations with } \\
\text { missing values-BMI: } 845 \mathrm{~kg} / \mathrm{m}^{2} ; \text {; CA: } 809 \text {; caste: } 660 \text {; education: } \\
627 \text {; assets quintile: } 18 \text {; occupation: } 643 \text {. } \\
\text { BMI, body mass index; CA, central adiposity; SAGE, Study on } \\
\text { global AGEing and adult health. }\end{array}$} \\
\hline
\end{tabular}

$5 \%$ among the poorest quintile, $(\mathrm{p}<0.0001)$. The corresponding prevalence of $\mathrm{CA}$ was $50 \%$ and $13 \%$ among the top and bottom groups, respectively $(P<0.0001)$. A clear trend was evident across wealth quintiles. EW was significantly more prevalent among the population that had 'no' caste $(16.8 \%)$ or belonged to 'other' caste $(16.3 \%)$, than ST $(7.5 \%)$ and SC $(6.5 \%)(\mathrm{p}<0.0001)$. The corresponding prevalence of CA was $43.9 \%, 37 \%$, $21.6 \%$ and $23.6 \%$, respectively $(\mathrm{p}<0.0001)$.

In the minimally adjusted models, greater household wealth, urban residence, higher education, privileged 


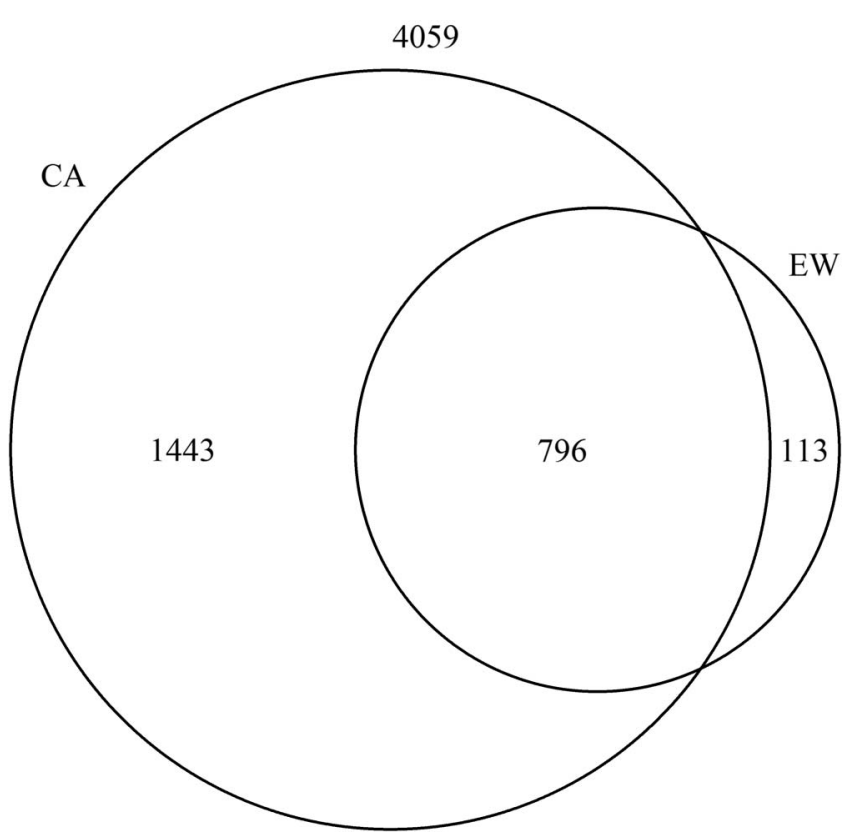

Figure 1 The prevalence of excess weight and central adiposity among older Indians aged 50 years or more.

caste and white-collared jobs, and also female gender, were all associated with greater odds of EW and CA in older Indians (tables 2 and 3). In the fully adjusted model, effect of education attenuated to almost null as attenuation of similar magnitude was also evident for occupation; whereas the effects of caste and setting were partially attenuated. The estimate of wealth also underwent partial attenuation, nevertheless, its independent effect was sizeable and eventually was the strongest among all the social determinants, as was evident from their standardised coefficients (see online supplementary table S1); OR for highest versus lowest quintile for EW 4.36 (3.23 to 5.95) and CA 4.39 (3.49 to 5.53). Tobacco use had negative association with both EW and CA. The gender risk factor interaction terms were not significant except for caste when CA was the outcome; upper caste women being significantly more likely to be affected with CA than upper caste men.

Approximately $40 \%$ of Indians (50+) suffered from hypertension. The tobacco and alcohol-adjusted OR of CA was 1.99 (1.78 to 2.23); after adjustment with BMI it was 1.63 (1.44 to 1.86). The overall BMI-unadjusted and BMI-adjusted PAF of hypertension, attributable to $\mathrm{CA}$, was $14 \%(126 \%$ to $16.2 \%)$ and $11 \% \quad(9.0 \%$ to $13.0 \%)$, respectively. The corresponding unadjusted and adjusted PAF in the lower $70 \%$ wealth bracket (hypertension: $36 \%$ ) was $15 \%$ and $12 \%$, respectively, and that among the wealthier $30 \%$ group (hypertension: $44 \%$ ) was $11 \%$ and $8 \%$, respectively. Among females (hypertension: 42\%), the probability of hypertension attributable to CA was as high as $13 \%$ (BMI unadjusted) and 12\% (BMI adjusted) (see online supplementary table S2).

\section{DISCUSSION}

Our study showed $14 \%$ older Indians had EW, while underweight was 2.5 times more prevalent. However, more than one of three older Indians possessed CA; and $\mathrm{CA}$ is considered an equally if not more important independent risk factor of cardiometabolic diseases. ${ }^{22}$ This indicates that accumulation of additional weight in later life among Indians was yet to assume substantial proportions compared to their undernutrition-related lack of appropriate body mass, albeit currently, the problem of abdominal fat accumulation manifested as CA was definitely not negligible among these older adults. This was even more significant because a sizeable proportion of these CA-affected older Indians had normal BMI, indicating abdominal girth being a more sensitive guide than weight-based metric, to measure obesity-related risk among older Indians.

What also becomes more significant from the public policy perspective is that not only one out of two older Indians in the top $30 \%$ wealth bracket has CA, but also, one of four among the less wealthy $70 \%$ possesses it. Even more remarkable is the distribution among older Indian women, every second of whom is affected with $\mathrm{CA}$, and where the wealth gradient for CA is narrower; $69 \%$ among the wealthier $30 \%$ and $46 \%$ in the less wealthy $70 \%$ of older women have CA.

Hence, perhaps for the first time, our study, from a nationally-representative sample of older Indians, illustrated that although a distinct positive economic gradient exists, obesity, especially the abdominal variety, is definitely no longer only restricted to affluent older Indians. The 'poorer 75\%' are also substantially affected, large sections of whom are believed to be still surviving on an average of US $\$ 2$ per day. ${ }^{32}$

Every 17th Indian aged 50 years or over suffered from CA-related hypertension, a fraction of which could be perhaps apportioned to their high BMI; but after accounting for BMI, 1 of 22 had prevalent hypertension exclusively attributable to CA. In the lower $70 \%$ wealth bracket, the BMI-adjusted and BMI-unadjusted portions of hypertension attributable to CA were of comparable magnitude. It must be considered that these benefits were estimated in terms of only one obesity-related outcome, hypertension, whereas far greater benefits may be achieved in terms of other obesity-driven conditions such as diabetes, cardiovascular disease and musculoskeletal disorders, which could not be evaluated here due to lack of their objective measures in the SAGE sample. This indicated that prevention and control of CA, which will also largely mitigate the EW problem, will benefit many older Indians across all socioeconomic strata.

Subramanian et $a l^{33}$ apprehended that any significant resource allocation to the control of non-communicable diseases in the current Indian context would deprive the poor, causing diversion of scant public health resources from control of infectious and childbirth-related diseases, which affect the vast majority of Indians, who are predominantly poor. They concluded that the burden of 
Table 2 Association of social determinants with excess weight in Indians aged 50 years and older in SAGE sample

\begin{tabular}{|c|c|c|c|}
\hline & $\begin{array}{l}\text { Excess weight } \\
\left(\mathrm{BMl} \geq 25 \mathrm{~kg} / \mathrm{m}^{2}\right) \\
n(\%)\end{array}$ & $\begin{array}{l}\text { Minimally adjusted* } \\
\text { OR }(95 \% \mathrm{Cl})\end{array}$ & $\begin{array}{l}\text { Fully adjusted† OR } \\
(95 \% \mathrm{Cl})\end{array}$ \\
\hline \multicolumn{4}{|l|}{ Age (years) } \\
\hline $50-59$ & $513(18)$ & 0.97 (0.96 to 0.98$)$ & 0.97 (0.96 to 0.98$)$ \\
\hline $60-80$ & $374(12)$ & & \\
\hline$>80$ & $25(9)$ & & \\
\hline \multicolumn{4}{|l|}{ Gender } \\
\hline Male & 341 (10.5) & 1 & 1 \\
\hline Female & $571(18)$ & 1.82 (1.57 to 2.12$)$ & 1.67 (1.34 to 2.07 ) \\
\hline \multicolumn{4}{|l|}{ Tobacco user } \\
\hline Never used & 592 (19.6) & 1 & 1 \\
\hline Ever used & $63(12)$ & 0.71 (0.53 to 0.95$)$ & $0.82(0.60$ to 1.10$)$ \\
\hline Current user & 257 (8.9) & $0.46(0.39$ to 0.54$)$ & 0.67 (0.56 to 0.80$)$ \\
\hline \multicolumn{4}{|l|}{ Caste } \\
\hline Scheduled Caste & $70(6.5)$ & 1 & 1 \\
\hline Scheduled Tribe & $29(7.5)$ & 1.11 (0.69 to 1.73$)$ & 1.27 (0.79 to 2.01$)$ \\
\hline Other & 627 (16.3) & 2.83 (2.20 to 3.70$)$ & 1.83 (1.40 to 2.43$)$ \\
\hline No caste or tribe & $183(16.8)$ & 2.94 (2.20 to 3.96$)$ & 1.95 (1.44 to 2.66$)$ \\
\hline \multicolumn{4}{|l|}{ Occupation } \\
\hline Traditional subsistence or unskilled & $296(8.9)$ & 1 & 1 \\
\hline Semiskilled & $136(15.4)$ & 2.01 (1.60 to 2.50$)$ & $1.21(0.95$ to 1.54$)$ \\
\hline Skilled or white-collar & $107(26.1)$ & 4.09 (3.15 to 5.28$)$ & 1.77 (1.31 to 2.37$)$ \\
\hline No paid occupation & $370(20.8)$ & 2.07 (1.72 to 2.50$)$ & 1.36 (1.11 to 1.66$)$ \\
\hline \multicolumn{4}{|l|}{ Education } \\
\hline Illiterate or up to primary & $584(11.9)$ & 1 & 1 \\
\hline Secondary & $239(20.2)$ & $2.63(2.18$ to 3.16$)$ & 1.26 (1.02 to 1.55$)$ \\
\hline Higher secondary and higher & 89 (28.2) & 4.37 (3.30 to 5.76$)$ & 1.17 (0.84 to 1.62$)$ \\
\hline \multicolumn{4}{|l|}{ Quintiles of asset } \\
\hline Lowest (0-4) & $70(5)$ & 1 & 1 \\
\hline Lower middle (4-6) & $134(9)$ & $1.70(1.26$ to 2.30$)$ & $1.42(1.04$ to 1.94$)$ \\
\hline Middle (6-8) & $203(13)$ & 2.74 (2.07 to 3.66$)$ & 2.01 (1.51 to 2.72$)$ \\
\hline Upper middle (8-10) & $234(21)$ & 4.84 (3.67 to 6.46$)$ & 2.83 (2.10 to 3.84$)$ \\
\hline Highest (10-16) & $270(30)$ & $8.02(6.08$ to 10.71$)$ & 4.36 (3.23 to 5.95$)$ \\
\hline \multicolumn{4}{|l|}{ Area of residence } \\
\hline Rural & 494 (10.3) & 1 & 1 \\
\hline Urban & $418(25.5)$ & 2.97 (2.57 to 3.44$)$ & 1.83 (1.55 to 2.16$)$ \\
\hline
\end{tabular}

chronic ailments and their risk factors is significant among the poor but $>$ largely restricted to the minority elite in India. Opponents argued ${ }^{12-15}$ that there are signs of 'reversal' of this positive socioeconomic gradient for chronic age-related diseases, claiming the poor are now more affected by them; hence their demand for significant public investment into non-communicable diseases. ${ }^{12}$ Our study, reflecting the national situation among older Indians as opposed to regional or predominantly urban results, suggests a cautious middle ground $^{14}$ in this "problematic discourse. ${ }^{33}$ Although a positive socioeconomic gradient for obesity was strongly evident among the current country-wide older population, the significant prevalence of CA, even among the older underprivileged and, especially, women, cannot be ignored. This certainly calls for a prompt populationbased policy response against obesity, especially with an eye towards its older population, which may enable them to lead a relatively morbidity-free and disabilityfree productive later life. Otherwise, delay in action can make the obesity problem too deeply entrenched and resource intensive to uproot, and, even worse, starts inequitably affecting the lower socioeconomic sections more, as has happened in many developed nations, the so-called 'reversal' of their socioeconomic gradient. ${ }^{4}$ However, all efforts should be made to preserve public investment for the 'unfinished business' of undernutrition and poverty-related diseases, which still affects a large section of the population, especially when they are young and in their reproductive ages.

From the crude and independent effects of various social determinants, and using a priori knowledge, we drew a causal link among social determinants leading to $\mathrm{CA}^{34}$ (figure 2). Calorie overconsumption and calorie 
Table 3 Association of social determinants with Central Adiposity in Indians aged 50 years and older in SAGE sample

\begin{tabular}{|c|c|c|c|}
\hline & $\begin{array}{l}\text { Participants with } \\
\text { central adiposity } \\
\text { n (\%) }\end{array}$ & $\begin{array}{l}\text { Minimally adjusted* } \\
\text { OR }(95 \% \mathrm{Cl})\end{array}$ & $\begin{array}{l}\text { Fully adjusted }+ \text { OR } \\
(95 \% \mathrm{Cl})\end{array}$ \\
\hline \multicolumn{4}{|l|}{ Age (years) } \\
\hline 50-59 & $890(30)$ & 0.98 (0.977 to 0.98$)$ & 0.98 (0.977 to 0.99$)$ \\
\hline $60-80$ & $815(25)$ & & \\
\hline$>80$ & $61(20)$ & & \\
\hline \multicolumn{4}{|l|}{ Gender } \\
\hline Male & $633(19.4)$ & 1 & 1 \\
\hline Female & $1622(50.8)$ & 4.23 (3.79 to 4.73 ) & 2.52 (2.14 to 2.99$)$ \\
\hline \multicolumn{4}{|l|}{ Tobacco user } \\
\hline Never used & $1099(36.1)$ & 1 & 1 \\
\hline Ever used & $129(24.3)$ & 0.79 (0.63 to 0.99$)$ & 0.90 (0.71 to 1.13$)$ \\
\hline Current user & 537 (18.6) & 0.50 (0.44 to 0.57$)$ & $0.69(0.60$ to 0.79$)$ \\
\hline \multicolumn{4}{|l|}{ Caste } \\
\hline Scheduled Caste & 255 (23.6) & 1 & 1 \\
\hline Scheduled Tribe & $85(21.6)$ & $0.88(0.65$ to 1.17$)$ & $1.26(0.90$ to 1.74$)$ \\
\hline Other & $1427(37)$ & 2.04 (1.74 to 2.41$)$ & 1.71 (1.41 to 2.09$)$ \\
\hline No caste or tribe & 483 (43.9) & 2.73 (2.24 to 3.32$)$ & 2.14 (1.71 to 2.68$)$ \\
\hline \multicolumn{4}{|l|}{ Occupation } \\
\hline Traditional subsistence or unskilled & $873(26.1)$ & 1 & 1 \\
\hline Semiskilled & $306(34.5)$ & 2.10 (1.76 to 2.49$)$ & $1.32(1.09$ to 1.60$)$ \\
\hline Skilled or white-collar & 177 (42.8) & $3.39(2.70$ to 4.26$)$ & $1.50(1.16$ to 1.94$)$ \\
\hline No paid occupation & $893(49.7)$ & $1.31(1.14$ to 1.50$)$ & $1.02(0.87$ to 1.19$)$ \\
\hline \multicolumn{4}{|l|}{ Education } \\
\hline Illiterate or up to primary & 1660 (33.5) & 1 & 1 \\
\hline Secondary & 441 (37.3) & 2.45 (2.09 to 2.87$)$ & $1.22(1.02$ to 1.45$)$ \\
\hline Higher secondary and higher & $154(48.3)$ & 4.42 (3.43 to 5.70$)$ & $1.30(0.97$ to 1.74$)$ \\
\hline \multicolumn{4}{|l|}{ Quintiles of asset } \\
\hline Lowest (0-4) & $226(20.1)$ & 1 & 1 \\
\hline Lower middle (4-6) & $440(28)$ & 1.70 (1.42 to 2.05$)$ & 1.64 (1.33 to 2.02$)$ \\
\hline Middle (6-8 assets) & $520(33.7)$ & 2.28 (1.91 to 2.74$)$ & 1.97 (1.60 to 2.42$)$ \\
\hline Upper middle (8-10) & 519 (46.5) & 4.28 (3.54 to 5.19 ) & 2.73 (2.19 to 3.41$)$ \\
\hline Highest (10-16) & 507 (56.3) & 6.73 (5.49 to 8.26$)$ & 4.39 (3.49 to 5.53$)$ \\
\hline \multicolumn{4}{|l|}{ Area of residence } \\
\hline Rural & $1410(29.2)$ & 1 & 1 \\
\hline Urban & 845 (51.4) & 2.72 (2.41 to 3.08 ) & 1.77 (1.54 to 2.03$)$ \\
\hline
\end{tabular}

underexpenditure were included in the causal diagram as the most proximate factors leading to CA, though these lifestyle characteristics were not objectively measured in the sample. The hypothesised causal links were empirically validated post hoc using Bayesian Network Learning ('bnlearn' package in R). ${ }^{35}$ The empirical results almost matched the a priori assumptions, however, the arc between caste and education was missing in the Bayesian Network (see online supplementary figure $\mathrm{S} 1$ ).

Our result describes wealth as the major driver of obesity having largest standardised coefficients in the fully adjusted model. Wealth-driven overconsumption has flourished within the culture of chronic food deprivation that Indian society had experienced for centuries; hence any form of socioeconomic advantage was utilised for accumulating extra calories. Also, socioeconomic prosperity was perhaps related to increased sedentariness. Privileged occupation and caste, major sources of inequity in Indian society, were positively associated with obesity, largely through increased wealth and sedentariness. Association between urban living and obesity was partly explained by clustering of obesogenic factors such as wealth, education and white-collared occupation in the cities, and partly mediated by the direct effect of a less active urban lifestyle with regard to commuting and daily chores.

Despite its effect attenuating substantially after adjustment for wealth and occupation, through which it is believed to affect obesity, educational achievement was yet to caste any direct protective antiobesity effect among older Indians, unlike in many middle and highincome countries, ${ }^{4}$ where cognitive and information processing skills acquired from education are believed to 


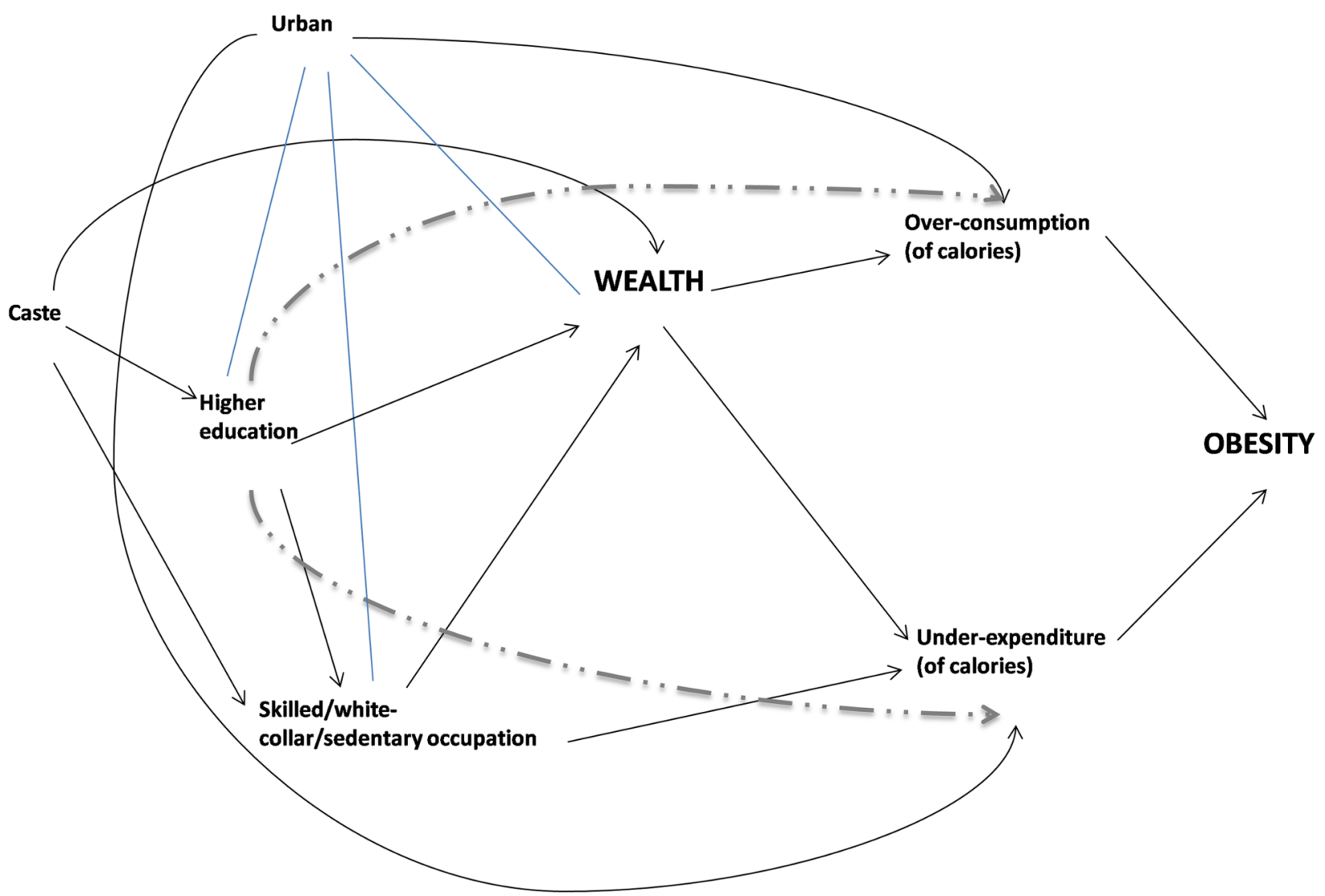

Figure 2 The association between obesity and its various social determinants. The solid arrows denote causal relationship; the lines without arrows denote association; the dotted arrows denote suggested protective pathways which should be utilised as a preventative antiobesity strategy.

help their citizens to negotiate the wealth-related overconsumption and underexpenditure of calories, marking the gradient 'reversal' in those societies.

Despite the entrenched, or also perhaps growing, wealth inequity in Indian society, ${ }^{36}$ a large number of underprivileged Indians-the 'lower 75\%,33_have undeniably benefitted from the post-nineties' economic growth; and, furthermore, the current economic environment of India will continue to increase the prosperity of many more Indians across all socioeconomic strata. Simultaneously, both calorie overconsumption and underexpenditure are likely to become more affordable and achievable to everyone through greater availability of calorie-dense industrially produced food at relatively cheaper prices, notwithstanding food inflation in the country; increasing automation of jobs and domestic chores even in the low-earning segment; and increased rate of urbanisation. This will accelerate the obesity burden in all strata of Indian society, though the 'reversal' of the positive socioeconomic gradient in the recent foreseeable future seems unlikely; this will only happen when the country crosses a certain economic developmental threshold, ${ }^{4}{ }^{5}$ enabling the protective effect of education to 'kick in'.

From the policy perspective, this growing obesity problem, affecting all societal strata, has to be confronted through investment in population-based public health initiatives, among which large-scale promotion for adoption, at all stages of life, of appropriate lifestyle, a component that is prominently missing from the current rudimentary Indian national programme for non-communicable diseases, should be prioritised. ${ }^{37}$ The societal aspiration for 'big size' and 'sedentariness' as signs of accomplishment ${ }^{38}$ may also have to be counteracted. Legislation against the food industry or development of active lifestyle-enabling urban infrastructure may follow. However, the first and foremost step would be to put obesity into the centre stage of the national sociopolitical discourse, so that Indians recognise it as a serious problem, as has been done recently with similar 'big ticket' societal issues in India, such as sanitation and toilet use.

In terms of future policy and research implications, targeted emphasis must be laid on Indian women, as they have substantially greater independent risk of obesity, which renders them more vulnerable to its dire health outcomes, especially disability, ${ }^{39}$ which may hinder their independent community living in later life.

Our study's limitation is its cross-sectional design, perhaps partly compromising our causal inferences. However, the described causal relations are so plausible that such bias, if any, is perhaps negligible. Also, among 
older Indians, the role of age-related frailty inflating the underweight segment and obscuring some of the obesitysocial determinant relationship, cannot be entirely ruled out. Detailed and objective measures of dietary habits including salt consumption and physical activity were not collected in the SAGE sample; these measures could have provided us with an opportunity to explore the role of these mediators in the pathway to excess weight, obesity and hypertension in this population.

The strength of our study is the India-wide generalisability, precise estimates and reliable measures ${ }^{40}$ from the large nationally representative SAGE sample; also emulating ELSA, SHARE and HRS designs, which helped to generate valuable chronic disease-related evidence with policy implications for the older population in those countries.

To conclude, our study has shown, for the first time, to the best of our knowledge, that obesity, mainly the abdominal variety, has a country-wide presence of significant proportion in the Indian population of individuals aged 50 years and older; and although the richer are more affected, the problem is also substantial in the lower socioeconomic stratum. Wealth being its strongest social driver and with ongoing economic growth of India, obesity is likely to increase rapidly in all the socioeconomic segments, unless acted on promptly, which should entail putting obesity into the national sociopolitical discourse and combating it through primordial population-based preventative actions.

Contributors SS conceptualised the study, extracted the data from the WHO-SAGE repository, conducted the analysis and interpreted the data, conducted a literature review for the study and wrote the first draft of the entire manuscript. PP participated in the analysis of the data and contributed to critically revising the manuscript. $A D$, conceptualised the study along with SS, and contributed to writing the initial proposal for extracting the data from the SAGE repository. He also contributed to analysis and interpretation of the data, and was a major contributor to the discussion section. He also critically revised the draft manuscript.

Funding Internally funded by Asian Institute of Public Health.

Competing interests None declared.

Provenance and peer review Not commissioned; externally peer reviewed.

Data sharing statement No additional data are available.

Open Access This is an Open Access article distributed in accordance with the Creative Commons Attribution Non Commercial (CC BY-NC 4.0) license, which permits others to distribute, remix, adapt, build upon this work noncommercially, and license their derivative works on different terms, provided the original work is properly cited and the use is non-commercial. See: http:// creativecommons.org/licenses/by-nc/4.0/

\section{REFERENCES}

1. Mazzocchetti A, Caranci N, Addis A. [Population ageing and health implication. Thinking time trends in Emilia-Romagna Region]. Recenti Prog Med 2014:105:191-7.

2. Reid CM, Thrift AG. Hypertension 2020: confronting tomorrow's problem today. Clin Exp Pharmacol Physiol 2005;32:374-6.

3. Pérez Rodrigo C. Current mapping of obesity. Nutr Hosp 2013;28 (Suppl 5):21-31.
4. Dinsa GD, Goryakin Y, Fumagalli E, et al. Obesity and socioeconomic status in developing countries: a systematic review. Obes Rev 2012;13:1067-79.

5. Monteiro CA, Moura EC, Conde WL, et al. Socioeconomic status and obesity in adult populations of developing countries: a review. Bull World Health Organ 2004;82:940-6.

6. Shukla A, Kumar K, Singh A. Association between obesity and selected morbidities: a study of BRICS countries. PLOS ONE 2014;9:e94433.

7. Manton KG. The global impact of noncommunicable diseases: estimates and projections. World Health Stat Q 1988;41:255-66. http://www.ncbi.nlm.nih.gov/pubmed/3232413 (accessed 17 Sep 2014).

8. Asia Pacific Cohort Studies Collaboration. The burden of overweight and obesity in the Asia-Pacific region. Obes Rev 2007;8:191-6.

9. Wang $\mathrm{Y}$, Chen $\mathrm{HJ}$, Shaikh $\mathrm{S}$, et al. Is obesity becoming a public health problem in India? Examine the shift from under- to overnutrition problems over time. Obes Rev 2009;10:456-74.

10. Yadav S, Arokiasamy P. Understanding epidemiological transition in India. Glob Health Action 2014;7:23248. http://www.ncbi.nIm.nih.gov/ pubmed/24848651 (accessed 18 Jul 2014).

11. Pandian JD, Srikanth V, Read SJ, et al. Poverty and stroke in India: a time to act. Stroke 2007;38:3063-9.

12. Prabhakaran D, Jeemon P, Reddy KS. Commentary: Poverty and cardiovascular disease in India: do we need more evidence for action? Int J Epidemiol 2013:42:1431-5.

13. Narayan KM, Ali MK. Commentary: Shielding against a future inferno: the not-so-problematic discourse on socioeconomic status and cardiovascular health in India. Int J Epidemiol 2013;42: 1426-9.

14. Jones-Smith JC. Commentary: Jumping the gun or asleep at the switch: is there a middle ground? Int J Epidemiol 2013;42:1435-7.

15. Stringhini S, Bovet P. Commentary: The social transition of cardiovascular disease in low- and middle-income countries: wait and see is not an option. Int $J$ Epidemiol 2013;42:1429-31.

16. Khadilkar VV, Khadilkar AV, Cole TJ, et al. Overweight and obesity prevalence and body mass index trends in Indian children. Int J Pediatr Obes 2011;6:e216-24.

17. Saha AK, Sarkar N, Chatterjee T. Health consequences of childhood obesity. Indian J Pediatr 2011;78:1349-55.

18. Kulkarni P, Nagendra, Ashok NC, et al. World health organization-body mass index for age criteria as a tool for prediction of childhood and adolescent morbidity: a novel approach in southern karnataka, India. Int J Prev Med 2014;5:695-702. http://www. pubmedcentral.nih.gov/articlerender.fcgi? artid=4085921\&tool=pmcentrez\&rendertype=abstract (accessed 18 Jul 2014).

19. Shah T, Purohit G, Nair SP, et al. Assessment of obesity, overweight and its association with the fast food consumption in medical students. J Clin Diagn Res 2014;8:CC05-7.

20. Samper-Ternent R, Al Snih S. Obesity in older adults: epidemiology and implications for disability and disease. Rev Clin Gerontol 2012;22:10-34. http://www.pubmedcentral.nih.gov/articlerender.fcgi? artid=3278274\&tool=pmcentrez\&rendertype=abstract (accessed 16 Jul 2014).

21. Zamboni M, Mazzali G, Zoico E, et al. Health consequences of obesity in the elderly: a review of four unresolved questions. Int J Obes (Lond) 2005;29:1011-29.

22. Sniderman AD, Bhopal R, Prabhakaran D, et al. Why might South Asians be so susceptible to central obesity and its atherogenic consequences? The adipose tissue overflow hypothesis. Int J Epidemiol 2007;36:220-5.

23. Wells JC. Commentary: Why are South Asians susceptible to centra obesity?-the El Niño hypothesis. Int J Epidemiol 2007;36:226-7.

24. O'Donnell CJ, Elosua R. Cardiovascular risk factors. insights from Framingham Heart Study. Rev Esp Cardiol 2008;61:299-310.

25. Basu S, Millett C. Social epidemiology of hypertension in middle-income countries: determinants of prevalence, diagnosis, treatment, and control in the WHO SAGE study. Hypertension 2013;62:18-26.

26. Kowal $\mathrm{P}$, Chatterji S, Naidoo N, et al. Data resource profile: the World Health Organization Study on global AGEing and adult health (SAGE). Int J Epidemiol 2012;41:1639-49.

27. Connor JH. Technical Description of the Health and Retirement Survey Sample Design. 1995. hrsonline.isr.umich.edu/sitedocs/ userg/HRSSAMP.pdf.

28. Steptoe A, Breeze E, Banks J, et al. Cohort profile: the English Longitudinal Study of Ageing. Int J Epidemiol 2013;42:1640-8.

29. World Health Organization. Waist circumference and waist-hip ratio. Report of a WHO expert consultation. Geneva: 2011. 
30. Brady AR. Adjusted population attributable fractions from logistic regression. Stata Tech Bull 1998;42:8-12.

31. R Development Core Team R. R: A Language and Environment for Statistical Computing. R Found Stat Comput 2011:1:409.

32. No Title. http://data.worldbank.org/indicator/SI.POV.2DAY/countries? page $=1$

33. Subramanian SV, Corsi DJ, Subramanyam MA, et al. Jumping the gun: the problematic discourse on socioeconomic status and cardiovascular health in India. Int J Epidemiol 2013;42: 1410-26.

34. Greenland S, Pearl J, Robins JM. Causal diagrams for epidemiologic research. Epidemiology 1999;10:37-48.

35. Thornley S. Using Directed Acyclic Graphs for Investigating Causal Paths for Cardiovascular Disease. J Biometrics Biostatistics 2013;4:182.
36. Subramanian SV, Subramanyam MA, Corsi DJ, et al. Rejoinder: Need for a data-driven discussion on the socioeconomic patterning of cardiovascular health in India. Int J Epidemiol 2013;42: 1438-43.

37. No title. http://pib.nic.in/newsite/efeatures.aspx?relid=76249

38. Case A, Menendez A. Sex differences in obesity rates in poor countries: Evidence from South Africa. Econ Hum Biol 2009;7:271-82.

39. Hosseinpoor AR, Williams JS, Jann B, et al. Social determinants of sex differences in disability among older adults: a multi-country decomposition analysis using the World Health Survey. Int J Equity Health 2012;11:52.

40. Kowal P, Biritwum R, Haldia K, et al. SAGE Working Paper No. 2. WHO Study on global AGEing and adult health (SAGE): Summary result of apilot in three countries. Geneva: 2012. 